\title{
Training through gametherapy promotes coactivation of the pelvic floor and abdominal muscles in young women, nulliparous and continents
}

\author{
Valeria Regina Silva 1, Cássio Riccetto 1, Natalia Miguel Martinho 1,2, Joseane Marques 1, Leonardo \\ Cesar Carvalho ${ }^{2}$, Simone Botelho ${ }^{1,2}$ \\ ${ }^{1}$ Departamento de Cirurgia da Faculdade de Ciências Médicas - Universidade Estadual de Campinas \\ (UNICAMP), SP, Brasil; ${ }^{2}$ Curso de Fisioterapia, Escola de Enfermagem, Universidade Federal de Alfenas \\ (UNIFAL-MG), MG, Brasil
}

\section{ABSTRACT}

Introduction and objectives: several studies have been investigated co-activation can enhance the effectveness of PFM training protocols allowing preventive and therapeutic goals in pelvic floor dysfunctions. The objective of the present study was to investigate if an abdominal-pelvic protocol of training (APT) using gametherapy would allow co-activation of PFM and transversus abdominis/oblique internal (TrA/OI) muscles. Patients and methods: Twenty-five nulliparous, continent, young females, with median age $24.76( \pm 3.76)$ years were evaluated using digital palpation (DP) of PFM and surface electromyography of PFM and TrA/OI simultaneously, during maximal voluntary contraction (MVC), alternating PFM and TrA/OI contraction requests. All women participated on a supervised program of APT using gametherapy, that included exercises of pelvic mobilization associated to contraction of TrA/OI muscles oriented by virtual games, for 30 minutes, three times a week, in a total of 10 sessions. Electromyographic data were processed and analyzed by ANOVA - analysis of variance.

Results: When MVC of TrA/OI was solicited, it was observed simultaneous increase of electromyographic activity of PFM ( $p=0.001)$ following ATP. However, EMG activity did not change significantly during MVC of PFM.

Conclusion: Training using gametherapy allowed better co-activation of pelvic floor muscles in response to contraction of TrA, in young nulliparous and continent women.

\section{ARTICLE INFO}

\section{Keywords:}

Pelvic Floor; Abdominal Muscles;

Electromyography

Int Braz J Urol. 2016; 42: 779-86

Submitted for publication: January 31, 2016

\section{Accepted after revision:}

February 01, 2016

\section{INTRODUCTION}

Pelvic floor muscles (PFM) are responsible for urinary and fecal continence mechanisms, and participate at sexual relations and delivery $(1,2)$. They also are important for pelvic stabilization, along with abdominal and lumbar muscles. Some studies (3-5) have demonstrated an intimate relation between PFM and the abdomen, particularly transversus abdominis muscle (Tra) whose impact on continence mechanisms and on pelvic floor functionality is being investigated in different phases of female vital cycle. Pereira et al. (5) have identified co-activation of those muscles in young 
asymptomatic nulliparous women, but not among pregnant and puerperal primiparous.

It is already known that any anatomic, biomechanical or neuromuscular alteration can trigger functional imbalancies with consequent urogynecologic disorders (6). Dysfunctions of pelvic floor are usually multifactorial. Age, pregnancy, delivery, hormonal alterations of female cycle as well as biomechanical and postural modifications (7) can influence PFM function.

Accordingly, it is assumed that reeducation of abdominal-pelvic compartment can be beneficial to prevent and or treat female pelvic floor dysfunction (7), justifying the proposal of protocols that include abdominal muscle training, mainly Tra muscle $(3,5,8,9)$.

The objective of the present study was to identify simultaneous electrical activity of PFM and transversus abdominis/oblique internal (TrA/ OI) in order to verify if a protocol of abdominal training (PAT) using gameteraphy would provide co-activation of those muscles.

\section{METODOLOGY}

Study type

Prospective, clinical study.

\section{Sample}

From January to June 2014, 25 young nulliparous continent women were recruited (median age $24.7 \pm 3.7$ years) through an informative lecture at Physiotherapy and Nurse schools of the Federal University of Alfenas - UNIFAL/MG. The study was approved by the ethical committee of the University of Campinas Medical School - UNICAMP (CAAE protocol: 19625113.5.0000.5404), and all participants signed a free consent form according to Helsinki Declaration. The study was authorized to be realized at the UNIFAL-MG.

\section{Inclusion criteria}

Nulliparous young female were included, with 18 to 35 years old, without any micturition complaints (score zero according to Portuguese validated question form International Consultation on Incontinence Questionnaire Short Form ICIQ UI-SF) (10).

\section{Exclusion criteria}

Exclusion criteria included virgin women (impossibility to apply electromyographic evaluation with endovaginal sensors); previous abdominal-pelvic surgeries; metabolic disorders (high blood pressure and diabetes); presence of myopathies and collagen diseases, neurologic alterations, cognitive disturbance and physical limitations that prevented participation; previous PFM training (supervised by a health professional); grade zero contractility of PFM, according to the Modified Scale of Oxford (11), without evident contraction of PFM.

\section{Evaluation procedures}

The study was performed by two investigators (VS and JM). Evaluations and revaluations were performed by a single researcher (JM) and the training protocol was applied by the main author (VS) who was unaware of the clinical conditions of the participants.

The participant was held in orthostatic position and the abdominal region was cleaned with 70\% alcohol; adherent and dischargeable sensors were positioned above the topography of TrA/OI muscles $(2 \mathrm{~cm}$ away from the antero-superior iliac spine towards pubis). The participants were instructed to correctly contract TrA/OI during expiratory phase, in dorsal decubitus with inflected inferior limbs.

Evaluation of PFM was initially performed by digital palpation, in order to graduate contractility according to Modified Scale of Oxford (11) and to orientate the participant on how to effectively contract PFM. Participants were asked to contract PFM while the evaluator pushed the fingers cranially during expiratory phase $(12,13)$ avoiding the use of gluteus and adductor muscles (5).

Electromyographic activity of PFM and TrA/ OI was recorded using an EMG equipment (EMG System do Brasil ${ }^{\Phi}$ ), consisting of a signal conditioner with a filter with frequencies of $20-500 \mathrm{HZ}$, amplifier of 1000x and rejection of common proportion of $>120 \mathrm{Db}$. Also, a conversion plate of A/D signal of 12 bit was used to convert analogic signs to digital signs, with sample frequency of filter $2.0 \mathrm{khz}$ and entrance band of $5 \mathrm{mv}$. All data 
were transmitted in microvolts ( $\mu v$ ) to the equipment software $(\mathrm{AqData})$ connected to a notebook processed in Root Mean Square (RMS) making sure that all electric equipments were turned off from electric network during collection of data (5).

PFM EMG was recorded using an endovaginal sensor (Physio-Med Services), manually introduced by the researcher with the aid of a hypoallergenic gel, positioned at the lateral wall of the vagina. Reference electrode was positioned at the right fist (between the radius and the styloid process of the ulna) (14).

Electromyographic evaluation protocol consisted on the recording of simultaneous collection of PFM (channel 1) and TrA/OI (channel 2 ), at rest, for 15 seconds, in order to use them during normalization of the electromyographic data, followed by three MVC (maximal voluntary contraction) of PFM, with simultaneous record of electromyographic response of $\mathrm{TrA} / \mathrm{OI}$.

After that, three MVC of TrA/OI with simultaneous recording of PFM response were performed. Each MVC was performed following a rest period of three minutes in order to avoid muscular fatigue (14).

\section{Abdominal - pelvic training program}

The protocol consisted of ten individual sessions of 30 minutes, supervised by the main investigator (physiotherapist) three times a week.

The exercises were performed emphasizing the abdominal-pelvic compartment using virtual games. This protocol was based on the work proposed by Martinho (2014), (15-17). It was used the Wii ${ }^{\mathrm{TM}}$ console and the game Wii Fit Plus ${ }^{\mathrm{TM}}$, using the sub-games: Lotus Focus, Penguin Slide, Table Tilt and Balance Bubble. The protocol was developed in order that the participant played seated on a Wii Balance Board platform positioned over an adjustable bench, allowing the knees and hips to form a flexion angle of 90o. In order to execute the games, many pelvic exercises that demanded trunk control using the abdominal muscles (TrA/OI) without active contraction of PFM were used (anteversion, retroversion, lateral pelvic inclination) (Figure-1).

Figure 1 - Movements are performed over the platform, during virtual games.

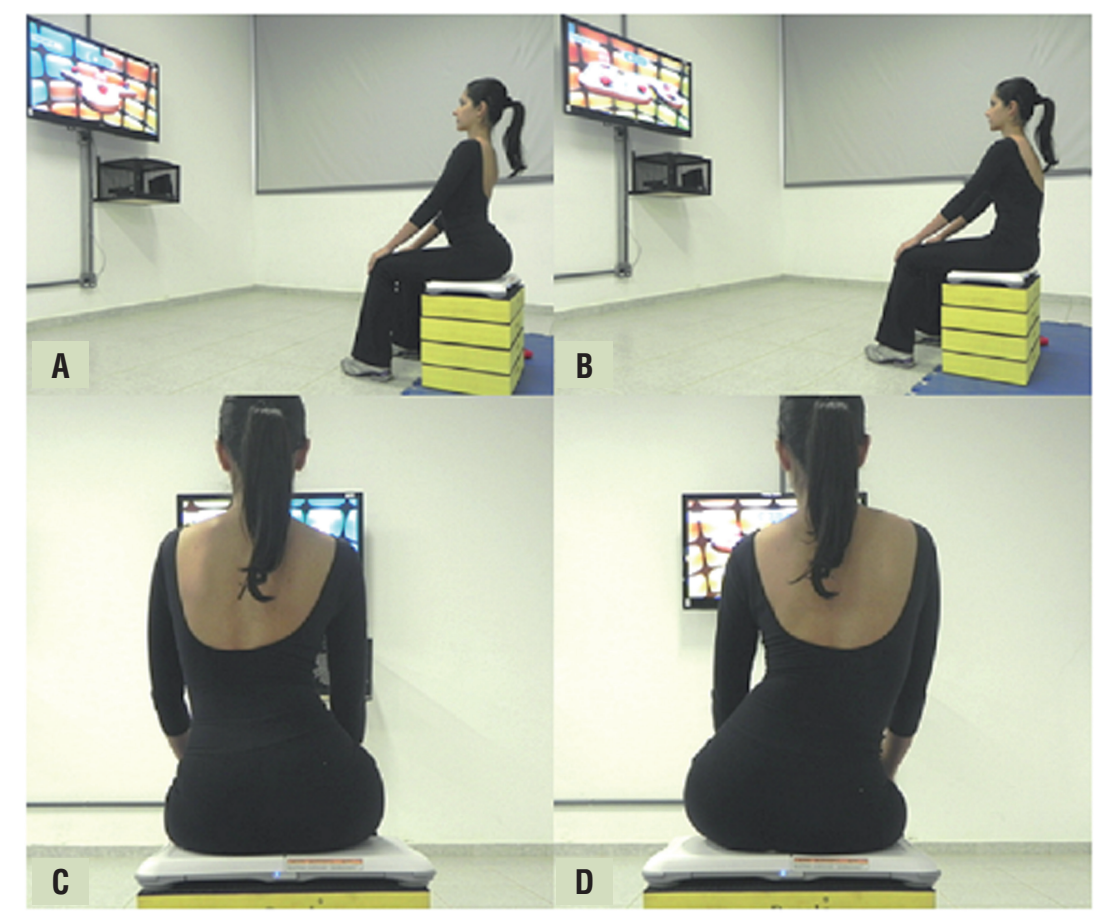

Anteversion movement $(A)$, retroversion (B), lateral pelvic inclination (D) 
Data processing and analysis

Initially, five seconds of each MVC were selected, considering the medium of three RMS (expressed in $\mu v$ ) for each participant. In order to investigate simultaneous electromyographic activity of PFM and TrA/OI (co-activation) it was calculated the percentage variation of activation related to rest of booth muscles, according to the following formulae (Figure-2):

Figure 2 - Calculus of percentage of variation in relation to rest.

$$
\begin{aligned}
& \text { Percentage } \\
& \text { activation }=\underline{\text { average of } 3 \text { CVM }- \text { repose value }} \times 100 \\
& \text { repose value }
\end{aligned}
$$

Statistical analysis was performed using ANOVA (analysis of variance), using the software SAS System for Windows (Statistical Analysis System), version 9.2. SAS Institute Inc, 2002-2008, Cary, NC, USA. Significance level was set at 5\%.

\section{RESULTS}

Table-1 presents clinical and social-demographic characteristics of participants.

During evaluation of PFM contractility using digital palpation, it was observed that most women presented contractions grade 3 or 4 according to Modified Scale of Oxford (11) (Table-2).

The main objective of this study was to investigate the presence of co-activation of PFM and TrA/OI before and after a program of ATP, using gametherapy. Table-3 present the results showing an increase of co-activation of PFM when it was solicited a maximal voluntary contraction of TrA/ OI after training.

\section{DISCUSSION}

PFM training has been recommended to prevent and treat female pelvic floor dysfunctions since

\begin{tabular}{|c|c|}
\hline \multicolumn{2}{|l|}{ Social-demographic characteristics } \\
\hline \multicolumn{2}{|l|}{ Color of the skin* $(\%)$} \\
\hline White & 92 \\
\hline Non white & 8 \\
\hline \multicolumn{2}{|l|}{ Schooling $^{*}(\%)$} \\
\hline Complete/incomplete higher education & 100 \\
\hline \multicolumn{2}{|l|}{ Marital status* $(\%)$} \\
\hline Single & 84 \\
\hline Married/stable union & 16 \\
\hline \multicolumn{2}{|l|}{ Work $^{* *}(\%)$} \\
\hline No labor & 76 \\
\hline Labor & 24 \\
\hline \multicolumn{2}{|l|}{ Income revenue* $(\%)$} \\
\hline 1-2 times a week & 16 \\
\hline 3-4 times a week & 20 \\
\hline$>4$ times a week & 64 \\
\hline \multicolumn{2}{|l|}{ Clinical characteristics } \\
\hline Age (years) $\left(M_{ \pm} S D\right)$ & $\begin{array}{l}24.76 \\
(3.76)\end{array}$ \\
\hline Body Mass Index $\left(\mathrm{Kg} / \mathrm{m}^{2}\right)(\mathrm{M} \pm \mathrm{SD})$ & $\begin{array}{l}22.34 \\
(3.70)\end{array}$ \\
\hline \multicolumn{2}{|l|}{ Physical activity (\%) } \\
\hline Sedentaries & 52 \\
\hline Active & 48 \\
\hline \multicolumn{2}{|l|}{ Sexual activity (\%) } \\
\hline Absent & 32 \\
\hline Present & 68 \\
\hline \multicolumn{2}{|l|}{ Stool movements (\%) } \\
\hline Less than 3 times a week & 20 \\
\hline Higher than 3 times a week & 80 \\
\hline
\end{tabular}

Table 1 - Social-demographic and clinical characteristics of participants.

1948, when Arnold Kegel (18) introduced the practice of repeatedly and singly contract those muscles.

Historically, PFM training programs oriented women to not contract abdominal, gluteus and adductor muscles, for those were considered accessory muscles (19). Until now, few anatomic 
Table 2 - Evaluation of contractility of PFM by digital palpation, before and after training.

\begin{tabular}{lccc}
\hline Modified Scale of Oxford & $\begin{array}{c}\text { Before training } \\
(\mathrm{f}-\%)\end{array}$ & $\begin{array}{c}\text { After training } \\
(\mathrm{f}-\%)\end{array}$ & $\begin{array}{c}\text { Time } \\
\text { P-value }^{*}\end{array}$ \\
\hline 1 & $1(4)$ & $0(0)$ & \\
2 & $4(16)$ & $2(8)$ & 0.0001 \\
3 & $13(52)$ & $13(52)$ & \\
4 & $7(28)$ & $9(36)$ & \\
5 & $0(0)$ & $1(4)$ & \\
\hline
\end{tabular}

Table presents distribution of participants according to Modified Scale of Oxford (presented data in absolute frequency-fe percentage-\%) and comparison between the time of evaluation before and after training.

*Wilcoxon test.

Table 3 - Co-activation of muscles in response to maximal voluntary contraction, before and after training.

\begin{tabular}{lccc}
\hline & Before training & After training & $\begin{array}{c}\text { Time } \\
\text { P-value }\end{array}$ \\
\hline Co-activation PFM (MVC TrA/OI) & 127.27 & 147.84 & 0.01 \\
Co-activation TrA/OI (MVC PFM) & 234.19 & 196.72 & 0.1 \\
\hline
\end{tabular}

Table presents muscular response (co-activation) following MVC of PFM or TrA/OI, comparing the time of evaluation before and after training. Values expressed in percentage (5). Note increase of co-activation of PFM when MVC was solicited to TrA/OI

PFM $=$ pelvic floor muscles

MVC = maximal voluntary contraction

$\mathrm{TrA} / \mathbf{O I}$ = transversus abdominis/oblique internal

*ANOVA for repeated measures with transformation by posts.

Power of sample: 0.06

and functional studies $(20,21)$ showed the true relation among muscles that form abdominal-pelvic compartment.

According to Piret and Beziers (2002) (20), transversus abdominis muscle is inserted in the same layer of transverse muscle of perineum. Delancey et al. (2004) (21) reported that in normal women increase of abdominal pressure promotes contraction of elevator anus muscle diminishing the genital hiatus. On the other hand, Junginger et al. (2010) (22) observed that bladder neck is elevated only when PFM contractions are higher than intra-abdominal pressure.

Caufriez (1997) (23) developed the hypo-pressure gymnastics technique that stimulates the recruitment of PFM following activation of abdominal muscles associated to diaphragmatic aspiration. But only after the studies of Sapsford At Hodges (2001) (8) the investigation of the relationship of those muscles were intensified and demonstrated that there is a co-activation of PFM during electrical activity of Tra (3-5). Neumman and Gil (2002) (3) showed that relaxing abdominal muscles prevents efficient contraction of PFM, suggesting a strong relationship among them.

Stupp et al. (2011) (24) in order to investigate if hypo-pressure gymnastic technique could trigger activation of both muscles-PFM and TrA-showed that MVC of TrA and PFM simultaneously is as efficient as isolated contraction of PFM.

In the present study, when co-activation of those muscles was analyzed, it was observed a significant increase of electrical activity of PFM following training, when MVC of TrA/OI was solicited. One of the hypothesis to explain that fact is the solicitation of maintenance of TrA contraction during the execution of exercises induced by virtual games, favoring co-activation of PFM; the performance of exercises in a virtual environment allows the participant to interact and feedback the 
real time activities. In this context, the use of gametherapy is been quite explored as biofeedback for physiotherapy treatment (15-17).

Kamel et al. (2012) (25) proposed training of abdominal muscles and observed significant improvement of PFM pressure evaluated by vaginal perineometer, suggesting indirect action of abdominal muscles on PFM activation, providing coordination, support and resistance. Rogers (2008) (26) described improvement of PFM perception following a training program justifying increase of co-activation of PFM.

On the other hand, in the present study it was not observed significant co-activation of TrA during MVC of PFM. Similar results were presented by Perschers et al. (2001) (27). Some factors could influence muscle synergy such as position of evaluation, which normally is different than the adopted position of daily activities, as well as the influence of posture in the order of muscular activation, also cited by Madill (2009) (28).

Specially in nulliparous young women, Pereira et al. (2013) (5) observed significant co-activation of both TrA/OI and PFM when MVC was solicited to both; however, co-activation was not observed in pregnant and puerperal women, suggesting the existence of other factors that influence the behavior of those muscles.

The study has some limitations, such as the small sample and reduced number of sessions. In spite of the fact that there is no consensus in literature regarding the ideal time of training to improve PFM functionality, Bø et al. (1990) (29) suggest improvement following six months of training.

Most studies investigate the effects of training in general in symptomatic women. Very few information is known regarding the pattern of muscular behavior of asymptomatic young women, who do not suffer interference of age, hormonal alterations, obesity, pregnancies and deliveries, as well of urogynecological signals and symptoms, one of the most important aspects of the present study.

Also, it is difficult to stablish in which condition it is more probable to observe positive results: while treating young asymptomatic women, with more probability of "normal" muscular performance or those with urogynecological symptoms who respond to treatment. These aspects can in- fluence treatment adherence and follow-up. In our study we observed good adherence. Participants reported satisfaction with the training, for it was innovative and stimulated PFM. No side effect was reported after training.

One of the challenges in this area is to introduce these trainings involving abdominal muscles for prevention, particularly PFM and TrA, in order to prevent overload of pelvic floor during daily activities. Pre-contraction of these muscles during daily activities that involve increase of intra-abdominal pressure (for example, sports or gymnastic) may be fundamental to prevent future dysfunctions, with improvement of quality of life and consequent reduction of treatment costs (30). Other studies must be performed in young and healthy populations to elucidate the effects of different kinds of training on anatomic and functional aspects of that population.

\section{CONCLUSIONS}

Abdominal-pelvic training using gametherapy improved co-activation of pelvic floor muscles in response to contraction of transversus abdominis and oblique internal, in young, continent nulliparous women.

\section{ABBREVIATIONS}

ANOVA = Analysis of variance

MVC = Maximal Voluntary Contraction

$\mathrm{SP}=$ Standard Deviation

EMG = Surface Electromyography

ICIQ-UI SF = International Consultation on Incontinence Questionnaire Short-Form

$\mathrm{PVM}=$ Pelvic Floor Muscles

OI = Oblique Internal

RMS = Root-mean-square

APT $=$ Abdomino-pelvic Training

$\operatorname{Tr} \mathrm{A}=$ Transversus abdominis

$\mu \mathrm{V}=$ microvolts

\section{ACKNOWLEGEMENTS}

We thank CAPES ("Coordenação de Aperfeiçoamento de Pessoal de Nivel Superior") and 
FAPEMIG ("Fundação de Amparo à Pesquisa do Estado de Minas Gerais”) (APQ-02199-15).

\section{CONFLICT OF INTEREST}

\author{
None declared.
}

\section{REFERENCES}

1. Pereira SB, Silva JM, Pereira LC: Treinamento dos Músculos do Assoalho Pélvico, In: Palma PCR, Berghmans B, Seleme MR, Riccetto CLZ, Pereira SB. Urofisioterapia. Aplicações clínicas das técnicas fisioterapêuticas nas disfunções miccionais e do assoalho pélvico. $2^{\mathrm{a}}$ ed. Personal Link. Curitiba. 2014; pp. 353-60.

2. Petros P, Riccetto CLZ: Aplicações clínicas da Teoria Integral da Continência. In: Palma PCR, Berghmans B, Seleme MR, Riccetto CLZ, Pereira SB. Urofisioterapia. Aplicações clínicas das técnicas fisioterapêuticas nas disfunções miccionais e do assoalho pélvico. $2^{a}$ ed. Personal Link. Curitiba. 2014; pp. 43-53.

3. Neumann P, Gill V. Pelvic floor and abdominal muscle interaction: EMG activity and intra-abdominal pressure. Int Urogynecol J Pelvic Floor Dysfunct. 2002;13:125-32.

4. Sapsford R. Rehabilitation of pelvic floor muscles utilizing trunk stabilization. Man Ther. 2004;9:3-12.

5. Pereira LC, Botelho S, Marques J, Amorim CF, Lanza AH, Palma $P$, et al. Are transversus abdominis/oblique internal and pelvic floor muscles coactivated during pregnancy and postpartum? Neurourol Urodyn. 2013;32:416-9.

6. Palma PCR, Portugal HSP: Anatomia do Assoalho Pélvico. In: Palma PCR, Berghmans B, Seleme MR, Riccetto CLZ, Pereira SB. Urofisioterapia. Aplicações clínicas das técnicas fisioterapêuticas nas disfunções miccionais e do assoalho pélvico. $2^{\mathrm{a}}$ ed. Personal Link. Curitiba. 2014;pp. 29-41.

7. Fozzatti MC, Palma P, Herrmann V, Dambros M. Impact of global postural reeducation for treatment of female stress urinary incontinence. Rev Assoc Med Bras. 2008;54:17-22.

8. Sapsford RR, Hodges PW. Contraction of the pelvic floor muscles during abdominal maneuvers. Arch Phys Med Rehabil. 2001;82:1081-8.

9. Bø K. Pelvic floor muscle training is effective in treatment of female stress urinary incontinence, but how does it work? Int Urogynecol J Pelvic Floor Dysfunct. 2004;15:76-84.

10. Tamanini JT, Dambros M, D’Ancona CA, Palma PC, Rodrigues Netto N Jr. Validation of the "International Consultation on Incontinence Questionnaire --Short Form" (ICIQ-SF) for Portuguese]. Rev Saude Publica. 2004;38:438-44.

11. Laycock J, Jerwood D. Pelvic floor muscle assessment: The PERFECT scheme. Phisyotherapy. 2001; 87:631-42.
12. Nagib ABL, Guirro EC, Palauro VA, Guirro RRJ. Avaliação da co-ativação da musculatura abdominopélvica em nulíparas com eletromiografia e biofeedback perineal Rev Bras Ginecol Obstet. 2005;4:210-5.

13. Hodges PW, Sapsford R, Pengel LH. Postural and respiratory functions of the pelvic floor muscles. Neurourol Urodyn. 2007;26:362-71.

14. Botelho S, Riccetto C, Herrmann V, Pereira LC, Amorim C, Palma P. Impact of delivery mode on electromyographic activity of pelvic floor: comparative prospective study. Neurourol Urodyn. 2010;29:1258-61.

15. Martinho NM. 0 treinamento por meio de realidade virtual melhora a funcionalidade dos músculos do assoalho pélvico de mulheres na pós-menopausa? Estudo controlado randomizado/ Natalia Miguel Martinho [tese]. Universidade Federal de Alfenas, MG: [s.n.], 2014.

16. Botelho S, Martinho NM, Silva VR, Marques J, Carvalho LC, Riccetto C. Virtual reality: a proposal for pelvic floor muscle training. Int Urogynecol J. 2015;26:1709-12.

17. Silva VR. Comportamento dos músculos do assoalho pélvico e transverso do abdômen/oblíquo interno frente a dois programas de treinamento abdominopélvico em mulheres jovens nulíparas, continentes: estudo controlado, randomizado/ Valeria Regina Silva [tese]. Universidade Estadual de Campinas, SP: [s.n.]. 2015.

18. Kegel AH. Progressive resistance exercise in the functional restoration of the perineal muscles. Am J Obstet Gynecol. 1948;56:238-48.

19. Bø K, Talseth T, Holme I. Single blind, randomised controlled trial of pelvic floor exercises, electrical stimulation, vaginal cones, and no treatment in management of genuine stress incontinence in women. BMJ. 1999;318:487-93.

20. Piret S, Béziers M.M. A coordenação motora: aspecto mecânico da organização psicomotora do homem. São Paulo (SP), Summus. 2002; p. 151

21. Wei JT, De Lancey JO. Functional anatomy of the pelvic floor and lower urinary tract. Clin Obstet Gynecol. 2004;47:3-17.

22. Junginger B, Baessler K, Sapsford R, Hodges PW. Effect of abdominal and pelvic floor tasks on muscle activity, abdominal pressure and bladder neck. Int Urogynecol J. 2010;21:69-77.

23. Caufriez M. Gymnastique abdominale hypopressive. Bruxelles. 1997; pp.8-10.

24. Stüpp L, Resende AP, Petricelli CD, Nakamura MU, Alexandre SM, Zanetti MR. Pelvic floor muscle and transversus abdominis activation in abdominal hypopressive technique through surface electromyography. Neurourol Urodyn. 2011;30:1518-21.

25. Kamel DM; Thabet AA; Tantawy SA; Radwan MM. Effect of abdominal versus pelvic floor muscle exercises in obese Egyptian women with mild stress urinary incontinence: A randomised controlled trial. Hong Kong Physiother J. 2012;31:12-8. 
26. Rogers RG. Clinical practice. Urinary stress incontinence in women. N Engl J Med. 2008;358:1029-36.

27. Peschers UM, Gingelmaier A, Jundt K, Leib B, Dimpfl T. Evaluation of pelvic floor muscle strength using four different techniques. Int Urogynecol J Pelvic Floor Dysfunct. 2001;12:27-30.

28. Madill SJ, Harvey MA, McLean L. Women with SUI demonstrate motor control differences during voluntary pelvic floor muscle contractions. Int Urogynecol J Pelvic Floor Dysfunct. 2009;20:447-59.
29. Bø K; Kvarstein B; Hagen RR; Larsen S. Pelvic floor muscle exercise for the treatment of female stress urinary incontinence: II. Validity of vaginal pressure measurements of pelvic floor muscle strength and the necessity of supplementary methods for control of correct contraction. Neurourol Urodyn. 1990;9:479-87.

30. Nappi RE, Davis SR. The use of hormone therapy for the maintenance of urogynecological and sexual health post WHI. Climacteric. 2012;15:267-74.

Correspondence address:

Simone Botelho, MD

Av. Jovino Fernandes Sales, 2600, Prédio A, Sala 107

Santa Clara, Alfenas,MG, 37130-000, Brasil Telephone: +55 35 3292-1899

E-mail: simone.botelho@unifal-mg.edu.br 